\title{
Japon bıldırcını yumurtalarında bazı dış ve iç kalite özellikleri arasındaki fenotipik korelasyonlar
}

\author{
Mahiye ÖZÇELIK
}

Fırat Universitcsi, Veteriner Fakültcsi, Zootekni Anabilim Dalı, Elałıığ

\begin{abstract}
Özet: Bu çalışma. bıldırcın yumurtalarında bazı dış ve i̧̧ kalite özellikleri arasındaki ilişkilcrin incelenmesi amaçıla

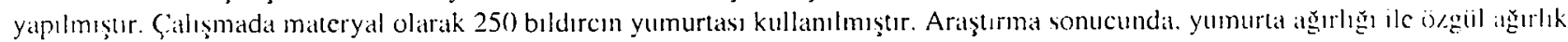

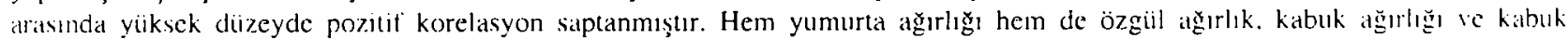

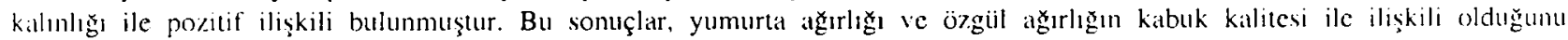
gösscrmiştir. Incelenen iç kalite özelliklerinden sarı yüksekliği, ak yüksekliği ve haugh birimi arasında pozitif ve istittistiki olarak

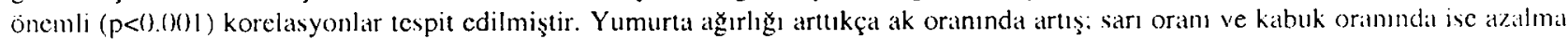

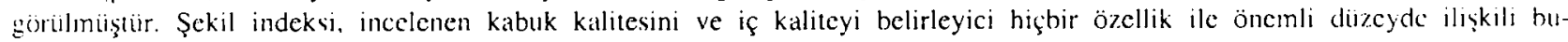
Iummamışur.

Anahtar kclimeler: Bıldırcun. korelasyon, yumurta kalite özellikleri
\end{abstract}

\section{The phenotypic correlations among some external and internal quality characteristics in Japanese quail eggs}

Summary: This study was conducted to investigate the relationships among some external and internal quility characteristics of quail cggs. A tolal of 250 quail eggs were used in the study. At the end of study, the highly positive correlation wals found hetween the egg weight and the specific grivity. Either $\mathrm{cgg}$ weight or specific gravity were positively related to shell weight and thell thickness. This results show that egg weight and specific gravity were related to egg shell quality. The positive and statisticatly significant $(p<0 .(0)\})$ corrclations were determined among yolk height. albumen height and halugh unit as internal quality chatacleristics. The albumen ratio was increased, but the yolk ratio and the shell ratio were decreased with increasing ege weight. The shape index was not significantly related to any egg shell quality and internal quality chatacteristics investigated in the study

Key words: Correlation. ceg quality characteristics, quail

\section{Giriş}

Yunurta öncelikle, kanatlıların kendi varlıklarının sürckliliğini sağlayan bir tohum olarak düşünülmelidir. Bu açıdan jakıldığında yumurtaya ait özcllikler, gelecek gencrasyonun verim özelliklerini sınırlayabildiği gibi, üreme güicij ve civciv kalitesini de etkilediği bilinen bir gerçeklir (28). Gerck tavuklarda $(10,15,18,19)$, gerekse biluircınlarda $(12,17,20,22,30)$ yumurtanın diş ve iç kalite ozelliklerinin çıkış gücünde, çıkıs ağırlığında ve gelişme perfermansında etkili emenler oldukları, özellikle kabuk kaliıssinin etkisinin yadsınamaz düzeyde olduğu bildirilmekledir.

Ayrucid, kanatl yumurtalarınun insan beslenmesinde önemli ve degerli bir gıda maddesi olması ve tïketicilerin hu guda maddesinde bazı nitelikleri arama istekleri de gerekli ve beklenen bir olgudur (28). Kırık ve çatlak kabuklu yumurtaların pazar şartlarını önemli düzcyde etkilediğ bilinen bir gerçektir. Yumurtalar üreticiden liiketiciye ulaşana kadar üretilen toplam miktarın \%7-8 kadarı kırılmakıadır (8). Öte yandan çatlak, kırık ve kabuk dayanıklılığı çok diuşiik olan yumurtalardan ku- luçkada faydalanma olanăğ da yoktur. Tüm bu nedenlerlc, gerck damızlıkçı birimler için kuluçka çalışmalarının verimliliği ve gelecek gencrasyonların verim izellikleri için, gerekse ticari yetiştiricilik için yunumtanın if̧ ve dış kalite özelliklerinin belirlenmesi ve bilinmesi kiçınılmazdır. Bu da sslahçıyı. üreticiyi, tuiketiciyi ve pazarla macıyı yönlendirici bir durumdur (28).

Günümüzde özellikle yumurta kabuk dayanıklılığını artırıcı çalışmalar, önemine bağlı olarak kendiliğ̣nden gündem konusu olmakta, kabuk kalitesinin bozukluğuna bağlı ekonomik kayıpları gidermek için kabuk kalilesini ıslah etme çalışmaları yapılmaktadır. Yumurla kabuk ka litesini belirleyen çok sayıda ozellik vardır. Bu özelliklerin başında yumurta ağırlığ lınlığı, kabuk ağırlı̆̆ gelmektedir. Ancak, bunlardan kabuk kalınlığ 1, kabuk ağırlığı ve kabuk sertliğinin helirlenmesinde kulllanılan deformasyon ve kırılma direnci gibi ozelliklerin öl çülmesi, ya özel düzeneklere bağlı ya cła yumurtanm biitünlügünün bozulnıasın gerektirnektedir. Bu nedenlerte günưmüzde ıslahçılar doğgrudan kabuk dayanıklılığını oflf̧- 
mek yerine, kabuk dayanıklılığ ile ilişkili olabilen diger özelliklerden yararlannı olanaklarını araştırmakıadırlar (21).

Yumurta ağırlı̆̆ının bir araştırıcı tarafından kabuk guicüne etkisi olmayan bir özcllik olarak bildirilmesine karşın (4), yumurta ağırlığı dolaylı olarak kabuk kalitesi ile ilişkilidir. Çünküi yumurta ağırlığının kabuk kalitesi ile doğrudan ilişkisi olan kabuk kalınlığı $(6,11,16,21,23)$ ve kabuk ağırlığı ile $(6,11,21)$ pozitif ilişkisi oldugu bildirilntektedir. Kabuk kalınlığı ve özgül ağırlığın da kabuk gücüne ctkisi olduğunu bildiren pek çok araştıncı vardır $(4,9,25,29)$

Bıldırcın, son yıllarda Türkiye'de yetiştiriciliği yaygunlaşan bir hayvansal protein kaynağıdır. Bu gelişme bıldıreın yumurtasına özgui dış ve iç kalite özelliklerinin de belirlenmesini, bu özellikler arasındaki ilişkilerin ve bu ozelliklerdc etkili olan genetik ve çevre ctmenlerinin paylarının tahmin edilmesini gerektirmektedir (28). Tavuklarda çoğunluğ kabuk kalitesiyle ilgili olmak üzere yumurtanın çeşitli dış kalite özellikleri $(13,14,18,21,24)$ ve hem dış hem de iç kalite özellikleri $(1,6,11,16,27)$ arasındaki ilişkilerin incelendiği çok sayıda çalışma bulundığu halde, bıldırcınlarda yumurtanın dış ve iç kalite ozzelliklerinin belirlendiği ve bunlar arasındaki ilişkilerin incelendiği çalışmalar yok denecek kadar azdır $(3,28)$.

Bu çalışmada bıldırcın yumurtalarında özellikle kabuk dayanıklılığı ve onunla ilişkili olduğu varsayılan yumurtanın bazı dış ve iç kalite özellikleri arasındaki ilişkilerin incelenmesi amaçlanmıştır.

\section{Materyal ve Metot}

\section{Materyal}

Araşurma materyalini 21 haftalık bıldırcınlardan alınan toplam 250 yumurta oluşturmuştur. Tartımlar için 0.01 g'a hassas elektrikli bir terazi, en ve boy ölçümleri için kumpas, yumurtanın iç kalitesini belirleyici ölçümlerde yüzeyi camdan yapılmış bir masa, sarı ve ak yükscklikleri için üç ayaklı bir mikrometre ve kabuk kalınlı̆̆ını ölçmek için de bu amaçla kullanılan bir mikrometre kullanılmıştır

\section{Metot}

Araştırma materyalini oluşturan yumurtalar, ard arda 3 günde toplanmıs ve yumurtlandıktan 1 gün sonra incelenmiştir (21). Yumurtalar önce numaralanarak tartılmış ve yumurta ağırlığı tespit edilmiştir. Daha sonra eni ve boyu ölçülmüş ve sudaki ağırlığı saptanmıştır. Bu işlemlerden sonra yumurtalar, cam bir masa üzerine kırılarak sarı yuiksckliği ve ak yükssekliği belirlenmiş, aktan ayrılan sarı, zarlı olarak tartılarak ağırlığı tespit edilmiştir.
Diğer yandan kabuklar, su alunda yıkanarak kalıntılardan temizlenmiş ve 24 saat havada kurumaya bırakılmışlardır. Kuruduktan sonra kabuk zarları ilc birliktc önce tartılarak ağırlıkları saptanmış, daha sonra sivri, kuiı uç ve ekvatoral bölgeden olmak üzere iiçer parça kabuk alınarak kalınlıkları ölçülmüş ve bu iiç ölçünuün ortalaması kabuk kalınlığı olarak kabul edilmiştir (26).

Bütün bu ölçümlerden yararlanılarak yumurtanın bazı özellikleri aşağıdaki formuiller kullanılarak heSaplanmıştır $(5.7,14,31)$;

\begin{tabular}{|c|c|}
\hline Şckil indeksi (\%) & $\begin{aligned}= & (Y u m u r t a n n \text { cni / Yumurtann boyu) } x \\
& 10(0)(14)\end{aligned}$ \\
\hline \multicolumn{2}{|c|}{ 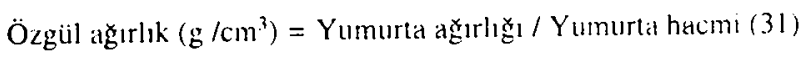 } \\
\hline Ak miktarı $(g)$ & 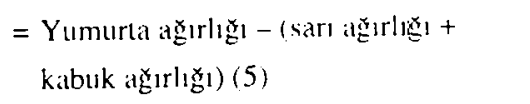 \\
\hline Ak oranı $(\%)$ & $=(A k$ ağgrlığl / Yumurta a ağ \\
\hline Sarı oranı $(\%)$ & 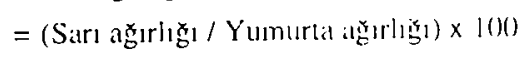 \\
\hline Kabuk oranı (\%) & 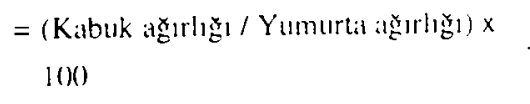 \\
\hline Haugh birimi & 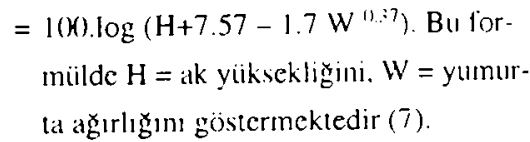 \\
\hline
\end{tabular}

Istatistik değerlendirmelerde. fenotipik korclasyon katsayılarının $\left(r_{p}\right)$ hesabı için Pcarson metodu uygulanmıştır (2)

\section{Bulgular}

Araşurmada incelenen yumurta kalite özelliklerine ait minimum, maksimun ve ortalama deg̣erler ile standart hata ve varyasyon katsayısı değerleri Tablo l'de, bu ozelliklerle ilgili fenotipik korelasyon katsayıları ise Tablo 2, 3 ve 4 ' de verilmiştir.

Araştırmada ortalama yumurta ağırlığ $10.52 \mathrm{~g}$, özgül ağırlık $1.01 \mathrm{~g} / \mathrm{cm}^{3}$, şekil indcksi \%79.54, kabuk agrlığ $0.76 \mathrm{~g}$, kabuk oranı \%7.25. ortalama kabuk kalınlığ $0.23 \mathrm{~mm}$, ak yüksekliği ve sarı yuiksckliği sırasıyla 3.64 ve $10.12 \mathrm{~mm}$, ak ve sarı oranı sirasıyla $\% 57.74$ ve 35.00 , haugh birini ise 85.35 olarak bulunmuştur

Dış kalitc özelliklerinden yumurta ağılığ 1 ile; özguil ağırlık, kabuk ağırlığı, ortalamı kabuk kalınlığı, kuiı ve ekvatoral bölge kabuk kalınlıkları arasında pozitif ve is tatistiki olarak önemli $(\mathrm{p}<0.01, \mathrm{p}<0.001)$ korelasyonlar bulunurken, yumurta ağırlığı ile; şekil indcksi re kabuk oranı arasındaki korclasyonlar düşük düzeyde negatif ve önemsiz çıkmıştır. Ö̌gül ağırlık; kabuk ağırlı̆ğ ile orta düzeyde; ortalama, küt ve ekvatoral bölge kabuk kalınlıkları ile düşük düzeyde pozitif fakat istatistiki olarak önemli $(p<0.01, p<0.001)$; şekil indeksi ve kabuk oram ile düşük düzeyde negatif ilişkili bulunmuştur. Kabuk ağılığı, kabuk oranı, ortalama. küt, sivri ve ekvatoral 
Tablo 1. Incelenen yumurta kalite özelliklerine ait ortalama, standart hata, minimum, maksimum ve varyasyon katsayısı de ğcrlcri.

Table 1. The values of mean, standart error, minimum, maximum and variation coefficient relating to investigated cge quality characteristics.

\begin{tabular}{|c|c|c|c|c|c|c|}
\hline Özcllikler & $\begin{array}{c}\text { Ortalama } \\
\bar{X} \\
\end{array}$ & \pm & $\begin{array}{l}\text { Standart hata } \\
5 \bar{x}\end{array}$ & $\begin{array}{c}\text { Minumum } \\
\text { değerler }\end{array}$ & $\begin{array}{c}\text { Maksimum } \\
\text { değerler }\end{array}$ & $\begin{array}{c}\text { Varyasyon } \\
\text { kiltsayıs }(\% \mathrm{~V})\end{array}$ \\
\hline \multicolumn{7}{|l|}{ Dis, kallice ijzellikleri } \\
\hline Yumurta ağırlığı (g) & 10.52 & & 0.048 & 8.00 & 12.60 & 7.65 \\
\hline 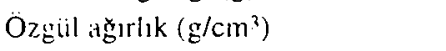 & 1.01 & & 0.004 & 0.78 & 1.18 & 6.83 \\
\hline Şekil indeksi $(\%)$ & 79.54 & & 0.167 & 71.43 & 89.65 & 3.49 \\
\hline Yumurta eni (cm) & 2.51 & & 0.004 & 2.30 & 2.70 & 2.74 \\
\hline Yumurta boyu $(\mathrm{cm})$ & 3.16 & & 0.007 & 2.90 & 3.50 & 3.71 \\
\hline Kabuk ağıılığı (g) & 0.76 & & 0.006 & 0.40 & 1.00 & 13.55 \\
\hline Kabuk oranı $(\%)$ & 7.25 & & 0.052 & 4.49 & 9.37 & 11.86 \\
\hline Orlalama kabuk kalınlığ (mm) & 0.23 & & 0.001 & 0.19 & 0.27 & 6.42 \\
\hline Kiit uç katuk kalınlı ț (mm) & 0.22 & & 0.001 & 0.18 & 0.28 & 8.35 \\
\hline Sivri uç kabuk kalınlığı $(\mathrm{mm})$ & 0.24 & & 0.001 & 0.19 & 0.28 & 8.21 \\
\hline Ekvatoral bölge kabuk kalınlığ (mm) & 0.23 & & 0.001 & 0.19 & 0.28 & 7.35 \\
\hline \multicolumn{7}{|l|}{ Ic kalite öz.cllikleri } \\
\hline Ak yijksekliği (mm) & 3.64 & & 0.032 & 2.03 & 5.13 & 14.44 \\
\hline Ak oranı $(\%)$ & 57.74 & & 0.263 & 38.23 & 69.83 & 7.48 \\
\hline Haugh birimi & 85.35 & & 0.183 & 74.59 & 93.73 & 3.56 \\
\hline Sarı yuiksckliği (mm) & 10.12 & & 0.028 & 8.75 & 11.04 & 4.63 \\
\hline Sarn oranı $1 \%$ ) & 35.00 & & 0.249 & 23.28 & 52.94 & 11.71 \\
\hline
\end{tabular}

Tabblo 2. Yuınurta dı̧ kalite özelliklerine ait fenotipik korelasyon katsayıları $\left(r_{p}\right)$

Table 2 . The phenotypic correlation cocfficients $\left(r_{p}\right)$ related to the external egg quality characteristics.

\begin{tabular}{|c|c|c|c|c|c|c|c|c|c|c|}
\hline Ozellikler & 1 & 2 & 3 & 4 & 5 & 6 & 7 & 8 & 9 & 10 \\
\hline Ozgiil ağırlık (2) & $.826^{* * *}$ & - & & & & & & & & \\
\hline Şekil indeksi (3) & $-.1\left(03^{0.12}\right.$ & $-.0150 ̈ .1)$. & - & & & & & & & \\
\hline Yumurta eni (4) & $.792^{* n+}$ & $.625^{*+*}$ & $.316^{* *}$ & - & & & & & & \\
\hline Yumurta boyu (5) & $687^{* *+}$ & $.480^{* * *}$ & $-.705^{-* *}$ & $.448^{* \cdots+}$ & - & & & & & \\
\hline Katbuk ağılığı (6) & $.491^{\cdots}$ & $.399^{\cdots \cdots}$ & $-.043^{\circ} \mathrm{D}$ & $.435^{* * *}$ & $.362^{* * *}$ & - & & & & \\
\hline Kabuk oraาı &.$-\left(179^{(0) 12}\right.$ & $-.074^{\circ} .0$ & $.015^{0.1}$ & $-.008^{0.15}$ &.$-(1230.1)$ & $.826^{* * *}$ & - & & & \\
\hline Ortalama k.abuk kalınligt (8) & $.185^{* *}$ & $.190^{* *}$ &.$\left(45^{0} .1\right)$ & $.215^{* \cdots}$ & $.110^{0.1)}$ & $.459^{* \cdots}$ & $.4(1) 6^{* * *}$ & $-\quad \cdot$ & & \\
\hline Kïl uç kalınlı̆̆ (9) & $.158^{* \cdots}$ & $.160)^{* *}$ & $-.0\left(03^{O D D}\right.$ & $.167^{* *}$ & $.122^{*}$ & $.364^{* \cdots *}$ & $.316^{* *}$ & $.820^{-\cdots+\cdots}$ & - & \\
\hline Sivri uç kalınlığı $(10)$ & $.0870 .11)$ & $.088^{\circ \mathrm{D}}$ & $.092^{O D D}$ & $.169^{* *}$ & $.036^{(0.1)}$ & $.295^{\circ \cdots}$ & $.283^{\cdots}$ & $.753^{\cdots}$ & $.341^{\cdots \cdots}$ & $\cdot$ \\
\hline Ekvatoral bölgc kalınlı ğ & $.212^{*+*}$ & $.222^{* * *}$ & (017 & $.184^{* *}$ & $.113^{0.1)}$ & $.463^{* * *}$ & .39()$^{\cdots * *}$ & $.848^{\cdots \cdots}$ & $.653^{\cdots}$ & $.440^{\cdots+\infty}$ \\
\hline
\end{tabular}

I: Yumurtia ağırlığı $\quad$ O.D. : Önemli değjl $\quad *: p<0.05 \quad * *: p<0.01 \quad * * *: p<0.001$

Tablo 3. Yuınurta iç kalite özelliklerine ait fenotipik korelasyon katsayıları $\left(r_{p}\right)$.

Table 3. The phenotypic correlation coefficients $\left(r_{f}\right)$ related to the internal egg quality characteristics.

\begin{tabular}{lllll}
\hline Özellikler & Ak yiiksckligi & Ak oranı & Haugh birimi & Sarı yüksckligi \\
\hline Ak oranı & $0.278^{\cdots * *}$ & - & & \\
Hatugh birimi & $0.974^{* *}$ & $0.224^{* *}$ & - & \\
Sarı yüksckli ğ & $0.485^{\cdots *}$ & $0.244^{* * *}$ & $0.428^{* * *}$ & - \\
Sarı oranı & $-0.284^{\cdots *}$ & $-0.980^{\cdots *}$ & $-0.230^{* *}$ & $-0.223^{\cdots *}$ \\
\hline
\end{tabular}

$*: p<0 .(0) \quad * * *: p<(0.00) 1$ 
Tablo 4. Yumurta dıs kalite özellikleri ile iç kalitc özellikleri arasındaki fenotipik korelasyon katsiayılann (ir). Titble 4. The phenolypic correlation coefficients $\left(r_{n}\right)$ between the external and internal egg quality characteristics.

\begin{tabular}{|c|c|c|c|c|c|}
\hline \multirow[b]{2}{*}{ Dly kalite ozellikleri } & \multicolumn{5}{|c|}{ lç kalite özelliklcri } \\
\hline & Ak yuiksekliği & Ak oranı & Haugh birimi & Sar! yuikscklig & Sarn orim \\
\hline Yumurta a derlis & $0.317^{\ldots \ldots *}$ & $0.279^{\cdots *}$ & $0.1(020.1)$ & $0.366^{\cdots}$ & $-1) .277 \cdots$ \\
\hline Ö/giil :tĕırhlk & $0.279^{\cdots}$ & $0.324^{\cdots+}$ & 0.1000 .10 & $0.309^{m b}$ & $-(1) .277: \cdots$ \\
\hline Sckil indeksi & $0.026^{0.13}$ & $0.014^{0.1)}$ & $0.0410 .1)$ & $-0.0(180.1)$ & -0.01190 .18 \\
\hline Yumurtil cni & $0.278 \cdots$ & $0.164 \cdots$ & $0.1040 .1)$ & $0.271^{\cdots}$ & $-(1) .170 \cdots$ \\
\hline Yumurtal boyu & $0.180^{\circ}$ & $0.1070 .1)$ & 0.0350 .12 & $0.2018 \cdots$ & $.0 .107^{0113}$ \\
\hline 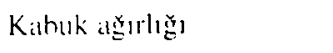 & $0.133^{*}$ & $-0.155^{*}$ & $0.126^{0.12}$ & 0.07100 & $-(0.01201)$ \\
\hline Kitbuk oram & $-0.045^{\circ 1)}$ & -() $.349^{+\ldots a}$ & $-(0.029 \mathrm{ob}$ & -0.154 & $0.15 ?^{\cdots}$ \\
\hline Ortalama kabuk kalınlığ & $0.199^{* *}$ & $0.177^{\cdots}$ & $0.166^{*}$ & $0.136^{\circ}$ & $-(1.2 ; 4 \cdots$ \\
\hline 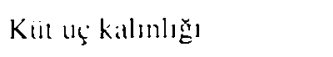 & $0.214^{+\cdots \cdots}$ & $0.170^{-\infty}$ & $0.186^{* *}$ & $0.167^{*}$ & $-0.246^{\cdots}$ \\
\hline Sivri uç kallınlıg్ğ & $0.119^{\circ}$ & 0.103 (0.1) & 0.1080 .12 & $0.045^{(0.1)}$ & $-0.170 \ldots$ \\
\hline likvatoral bölge kalmhly & $0.147^{\circ}$ & $0.158^{* *}$ & 0.1060 .12 & $0.120)^{-}$ & -0.250 \\
\hline
\end{tabular}

Ö.I : Öncmli deṣ̌l $\quad *: p<0.05 \quad * *: p<0.01 \quad * * *: p<0.0(0) 1$

bölec kabuk kalınlıkları arasında yüiksek veya orta düzeyde pozitif korelasyonlar saptanmıştır (Tablo 2).

lç kalite özelliklerinden ak yükseklił̣̆i, ak oranı, haugh birimi ve sarı yüksckliği arasında pozitif, sarı oranı ile incelenen diğer iç kalite özellikleri arasında ise negatif korelasyonlar tespit edimiştir. Incelenen tün if̧ kalite ozellikleri arasindaki korelasyon katsayılan istatistiki olarak öncmli bulunmuşı ( $\mathrm{p}<0.01$ ve $\mathrm{p}<0.001$. Tablo 3).

Yumurta ăğılığı ve özgiil ağırlık ile; sarı oranı arasmola negatif. bu iki özellik ile incelenen diğer tüm iç kalite o\%ellikleri arasında poritif korelasyonlar bulunmuşıur. Kabuk oranının ak yüksckliği, ak oranı, haugh birimi ve sarı yüksekliği ile neg̣atif, sarı oranı ile pozitif ilişkili olduğg saptanırken, kabuk kalınlıkları ile; sarı oranı hariç incelenen iç kalite özellikleri arasında pozitif yönlü korelasyonlar tespil edilmiştir (Tablo 4).

\section{Tartışma ve Sonuç}

Araşturma sonucunda; yumurta ağırlı̆ğı kabuk kalınlığı, kabuk ağğılığı ve oranı, şekil indeksi, ak yüksekliğ̣j. ak oranı, haugh birimi. sarı yuiksckliği ve oranı oxelliklerine air elde edilen ortalana değerler, Uluocak ve ark.(28)'nın araştırma bulgularına yakın çıkmışur. Araşırmada yumurta ağırlığı arttıça özgül ağırlığın önemli đuizeyde artığı, şekil indeksinin ise önemsiz düzeyde a\%aldığ saptanmıştır. Çünkü, yumurta ağırlığı ile azguil ağırlık arasında yüksck dïzeyde pozitif (0.826), yumurla ağırlığ ile şckil indeksi arasında ise düşük düzeyde negatif (-0.103) korelasyonlar bulunmuştur. Poyraz (21) da yaptığı araştırmada yumurta ağırlığı ile şckil indeksi allasında negatif korelasyon bildirmiştir.

Kabuk å̆ırlı̆̆ ve kabuk kalınlığmın yumurta ağırl,ğ arışına paralel bir artış göstermesine karşılık, yumurla içindeki kabuk oranının ağırlık artışı ile ters oran- t1lı olarak değiştiği göruilmiiş̧ür. Bu durun, kalbuk miktarı ve kalınlığgndaki yumurta ağırlığına bağ nurtayı meydana getiren öteki unsurların arışından daha az olnasından kaynaklanmaktadır. Işcan ve Akcan (11) da yumurta ağırlığının kabuk oranı ile negatil yönde ilişkili olduğunu (-0.26) bildirmişlerdir. Yumurla ağırlı̆̆ do laylı olarak kabuk kalitesi ile ilişkili olan bir özelliktir. Çünkui yumurta ağırlığının kabuk kalitesi ile doğrudan ilişkisi olan kabuk kalınlığı $(6,11,16,21,23)$ ve kabuk ağırlığı ile $(6,11,18,21)$ pozitif ilişkisi oldığgu bildirilmektedir. Bu çalışmada da litcratuir bilgi clog̣ rultusunda sonuçlar elde edilmiştir (Tablo 2). Nitekim, Işcan ve Akcan (11) ile Poyraz. (2l) da, yumurta ağar lığının hem kabuk ağırlı̣̆̆ hem de kabuk kalınlığ ile ilişkisinin pozitif ve önemli olduğunu. Choi ve ark. (6) yumurta ağırlığı ile kabuk ağırlığı arasında yuiksek pozitif korclasyon (0.53) olduğunu, Stadelman (23) ve Mutal (16), yumurta ağırlığı ile kabuk kalınlığı arasında pozilif (srrasiyla 0.26 ve 0.129 ) korelasyonlar olduğunu bildirmektedirler. Bu nedenle, kabuk ağırlığı ve kabuk ka lınhığının hem yumurta kırıldıktan sonra đilçülebilen özel likler olması, hem de ölçümün zaman alması nedenleriyle kabuk kalitesini tespitte bu özcllikler yerinc. yumurta ağırlığ değgerlerinin doğrudan kullamlahileceğ sioylenebilir.

Yumurta ağırlığına benzer şckilde, ïzoüil ağırlık da kabuk ağırlığı jle orta düzeyde, kabuk kalınlığı jle diişük düzcyde pozitif ilişkili bulunmuşur. Bu bulgular da çoğu araşturma sonuçları ile bir uyumluluk içindedir. Çünkü özgül ağırlık ile kabuk kalınlığ sinda sirasiyla 0.31 ve 0.09 (11), 0.74 ve 0.61 (13). 0.8796 ve 0.6121 (21); örgül ağılık ile kabuk kalınlığ arasinda 0.80 (6.19). 0.63 (24) gibi pozilif korclasyonlar olduğu ve bunun rutin çalışmalarda kullanılabilecẹğ bil 
dirilmektedir. Bu bulgular, özgül ağırlı̆̆ın da kabuk ağırllğ̣ı ve katıuk kalınlığı yerine kullanılabileceğini gösternektedir

Şekil indeksi, kabuk kalitesini belirleyici hiçbir özellik ile c̈nemli düzeyde ilişkili bulunmamışır. Poyraz (21) da yaptı̆̆ araştırmada şekil indeksi ile kabuk esnekliği, katuk kalınlığı ve kabuk ağırlı̆̆ı arasındaki korelasyonları oldukça düşük düzeyde bulmuştur. Araştırmada ortalama kabuk kalınlığı; küt, sivri ve ekvatoral bölge kabuk kalınlıkları ilc; küt, sivri ve ekvatoral bölgede ölçülen kabuk kalınlıkları da kendi aralarında yüusek düzeyde: (küt uç kahınlığı, sivri uç kalınlığı ile orta düzcyde) pozitif ilişkili bulunmuştur (Tablo 2). Bu sonuç, kabuk kalınlığını belirlemede tek bir bölgede ölçüm yapmannn yeterli olabileceğini göstermektedir (1). Bu da ölçümün daha az zaman almasını sağlayacaktır.

Incelenen iç kalite özclliklerinden ak yüksekliği, ak orani, haugh birimi ve sarı yüksekliği arasında pozitif korelasyonlar saptanmıştır (Tablo 3). Bu sonuca göre, sarı yüksekliği arttıkça yani küremsi sarılı yumurtalarda ak kalitesinin iyileştiģi, akın daha yogun ve yüksek olduğu ve haugh biriminin iyileştiği söylenebilir. Çünkü ak yüksekliği, en önemli iç kalite ölçüüu olan haugh biriminin hesaplanmasında kullanılan ve yoğun albümin kalitesi hakkında bilgi veren bir parametredir. Nitekim, bir araşurmada da sarı yüksekliği ile ak yüksekliği arasında (0.482), sarı yüksckligi ile haugh birimi arasında (0.515) ve ak yüksekliği ile haugh birimi arasında (0.972) bu araştırma bulgularına oldukça yakın düzeyde pozitif korelasyonlar bildirilmiştir (1).

Araştırmada incelenen yumurta dış kalite özellikleri ile iç kalite özellikleri arasındaki fenotipik korelasyon katsayıları da hesaplanmış ve Tablo 4'de verilmiştir. Yumurta ağırlığı ve özgül ağırlık artışına paralel olarak ak yüksckliği, ak oranı, haugh birimi ve san yüksekliğinde artma, fakat san oranında azalma görülmüştür. Kabuk

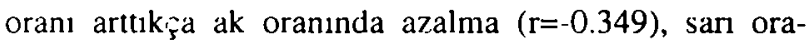
nında ise bi:-az artı̧̧ $(r=0.157)$ oldugu tespit edilmiştir. $\mathrm{Bu}$ sonuçlara gijre, yumurta ağırlığındaki değişime bağlı olarak yumurtayı oluşturan ak, san ve kabuk gibi temel kusımlann miktar ve oranlarının da değiştiği, fakat sarı ve kabuk oranlarının, ak oranının tersine birlikte deģişim gösterdiği söylencbilir. Bu sonuç, bir araştırma bulgusu ile de desteklenmektedir (11). Şekil indeksi, incelenen hiçbir iç kalite özelliğ̣i ile önemli düzeyde ilişkili bulunmamıştır. Yumurtanın eni ve boyu arttıkça ak yüksekliği, ak oranı ve haugh birimi ile sarı yüksekliğinde artma görülmektedir. Ancak, bu iç kalite özellikleri ile yumurta eni arasındaki korclasyonlar, yumurta boyu ile olan korelasyonlardan daha büyük çıkmışır. Bu sonuç da, yumurtanın boyuna göre eni artukça ak ve sarı yükseklikleri ile haugh biriminin daha fazla arttığını, yani yumurta iç kalitesinin daha iyi olduğunu göstermektedir.

Sonuç olarak; bıldırcın yumurtalarında da yumurta ağırlı̆ındaki değişime bağlı olarak yumurtayı oluşturan temel kısımların (kabuk, ak, sarı) yumurta içindeki niktar ve oranlarının değiştiği, yumurta ağırlı̆̆ı ve özgül ağırlığın dolayh olarak kabuk kalitesi ile ilişkili olduğu, bu nedenle kabuk kalitesini belirlemede yumurta ağırlığı ve özgül ağırlık özclliklerinden yararlanılabileceği kanısına varılmışur.

\section{Kaynaklar}

1. Akbaş Y, Altan Ö, Koçak Ç (1996): Tavuk yusımun tavuk jumurtasının iç ve dıs kalite özellikleri üzerine elkileri. Tr J Vet Anim Sci, 20, 455-460.

2. Apaydm A, Kutsal A, Atakan C (1994): Uygulcmall lstatistik. Ankara.

3. Başpınar E, Yıldız MA, Özkan MM, Kavuncu O (1997): Japon bildırcin yumurtalarinda yumurta ağirlığı lie şekil indeksinin kuluçka özelliklerine etkisi. Tr J Vet Anim Sci. 21, 53-56.

4. Buss EG (1982): Genetic differences in avian egg shell formation. Poultry Sci, 61, 2048-2055.

5. Carter TC (1968): Egg Qualin;; A Study of Hen's Egg. Oliver and Boyd Lid, Edinburgh.

6. Choi JH, Kang WJ, Baik DH, Park HS (1983): A study on some characteristics of fraction.s and shell quality of the chicken egg. Korean J Anim Sci, 25, 651-65.5.

7. Csuka J, Ledec M (1981): Egg quality evaluation by selected physical markers. Rocz Nauk Zoot T, 8, 45-58.

8. Hamilton RMG (1982): Methods and factors that affect the measurement of egg shell quality. Poultry Sci. 61. 2022-2039

9. Hunt JR, Voisey PW, Thompson BK (1977): Physical properties of egg shells: A comparison of the puncture and compression tests for estimating shell strength. Can J Anim Sci, 57. 329-338.

10. Hurnik GG, Renhart BS, Hurnik JF (1978): Relationship between albumen quality and hathability in fresh and stored hatching egg.s. Poultry Sci. 57, 854-857.

11. Işcan KM, Akcan A (1995): Broyler parent yumurtalarmda yumurta ă̆ırlığı, yumurta özgül ăgırliğt ve bazı yumurta kısımları arasındaki iliskkiler. Hayv Araşı Derg, 5, 49-52.

12. Marks HL (1975): Relationship of emhnomic development to egg weight, hatch weight and growth in Japanese quail. Poultry Sci, 54, 1257-1262.

13. Marks HI, Kinney TB (1964): Measures of egr shell quality. Poultry Sci, 43, 269-271.

14. Masic B, Zigic L, Srajber L, Marinkovic V (1972): Corrrelations between shape index and shell deformation of hens eggs over a laying year. Brit Poultry Sci, 13, 185-189.

15. McDaniel GR, Roland DA, Coleman MA (1978): The effect of egg shell quality on hatchability embrimic mortality. Poultry Sci, 58, 10-13.

16. Mutaf Y (1976): Tavuk Yumurtalarmanda Kaliteyi Oluşturan Özelliklere Ait Genetik Parametre Tahminleri Üzerinde Arasstırmalar. Doktora tezi, Izmir. 
17. Narahari D, Abdul- Mujev $\mathbf{K}$, Thangavel A, Ramamurty N, Visunathan S, Mohan B, Muragananda B, Sundararosu $\mathbf{V}$ (1988): Traits influencing the hatching performance of Japanese quail eggs. Brit Poultry Sci, 29. 101-112

18. Nordstrom JO, Ousterhout LE (1982): Estimating of shell weight and shell thickness from egg specific gravity and egg weight. Poultry Sci. 61, 1991-1995.

19. Peebles ED, Brake J (1987): Egg shell quality and hatchathility in broiler breeder egg.s. Poultry Sci. 66, 596-604.

20) Pecbles ED, Marks HI (1991): Effects of selection for growth aind selection diet on egg shell quality and embronic development in Japanese quail. Poultry Sci, 70. $1471-1480$.

21. Poyraz Ö (1989): Kabuk kalitesi ile ilgili yumurta ïzellikleri arastndaki fenotipik korrelasyonlar. Lalahan Hayv Arasţ Enst Derg: 29. 66-79.

22. Skewes PA, Wilson HR, Mather FB (1988): Correlations anomy egn weight, chick weight and yolk sac weight in Bobwhite quail (Colinus virginianus). Florida Sci, 51, 159162.

23. Stadelman WJ (1986): The Preservation of Quality in Shell Eggs. In: WJ Stadelman. OJ Cotteril (Eds), Egg Science and Technology. Avi Puplishing Com Inc Westport, Connecticut.

24. Thompson BK, Grunder AA, Hamilton RMG, Hollands KG (1983): Repeatability of egg shell quality measurements within individual hens. Poultry Sci, 62, 23092314.
25. Thompson BK, Hamilton RMG, Voisey PW (1981): Relationships among various egg maits relating to shell strength anong and within five arian species. Poultry Sci. 60, 2388-2394.

26. Tyler C (1961): Shell strength: Its measurement and its relationship to other factors. Brit Poultry Sci. 2. 3-19.

27. Uluocak AN (1990)): Beyaz yumurtalarda bazl kalite ozellikleri arasmdaki iliskiler. Çukurova Univ Zir Fak Derg. 5 87-96.

28. Uluocak AN, Okan F, Efe E, Nacar H (1995): Bildircm yumurtalarmda bazl dis be is katite izellikleri ile bunkarm jaşa göre değişimi. Tr J Vet Anim Sci, 19. 181-185.

29. Voisey PW, Hamilton RMG (1976): Factors affecting the nondestructive and destructive methods of measuring es. shell strength by the quasistatic compression test. Brit $\mathrm{Po}$ uliry Sci, 17. 103-124.

30. Yannakopoulos $\mathbf{A I}$, Tserveni-Gaousi AS (1987): Effect of breeder quail age and egg weight on chick wiaght. Brit Poultry Sci, 66, 1558-1560).

31. Yaldaz N (1983): Yumuract Ticari Hibrit Bir Faruk Sürüsünde Basl Verim Özellikleri ile Ilgili Fenstipik Parametreler ve Yumurtlama Modeli. Doktora tczi. Elatzığ

Gelis tarihi : 2.2.2001/Kahul tarihi : 29.5.2001

Yazışma adresi:

Doş: Dr. Mahive Öz.̧elik

Firat Universitesi, Veteriner Faküliesi

Zootekni Anahilim Dalt. Elazığ 